\title{
Observations on the Laryngeal Muscles of Madam Tamaki Miura, Primadonna of the "Madam Butterfly"
}

\author{
By \\ Koichiro Oishi \\ (Clinic of Oto-Rhino-Laryngology, Affiliated Hospital of Tokyo University \\ Medical School)
}

The larynx is one of the principal parts of the vocal mechanism. As far as its anatomical structure is concerned, man and anthropomorphous apes show no essential differences ${ }^{(1)}$. Therefore, this organ can hardly be expected to show any fundamental differences in type of development in men of great singing abilities as compared with ordinary men. However, qualities of the voice vary considerably among individuals of the same size; age and sex. This is undoubtedly due to delicate and yet intricate differences in anatomical details of the larynx in different individuals, and furthermore, as generally known, individualities exist to more or less extent in the laryngeal muscles automatically and involuntarily controlling the vocal cords, the generator of proper tones and in groups of muscles which act as their attributes. These are sometimes left out of description as meaningless fibers of the muscles and they are sometimes treated as variant or independent muscular bundles.

It is, of course, impossible to find from the results of dissections the relation between actions of the muscle fibers or bundles that may be placed in the category of individual variations and the tonal qualities of one's voice, unless the phonetical history of the larynx specimen is thoroughly known. But even if its history is known in details, the problem would still remain to be a difficult one at the present state of our knowledge.

Good larynx or good vocal cords may be a potential element for a great singing artist; but it should be emphasized that nothing is known yet to indicate that any of his muscles in these regions are 
developed more than in ordinary men. However, we have observed by laryngoscopy vocal cords and actions and forms of the laryngeal cavity that seem to be well suited for vocal musics and have found these more frequently in excellent singers.

If a large number of larynx of great singers were collected, comparative studies of their anatomical details would lead to a good understanding of the relation of morphology to phonation. A rare chance to approach this problem presented itself to me when I had an opportunity to carry out anatomical dissections of the larynx of Madam Tamaki Miura, a world-famous opera-singer of the Madam Butterfly.

I have dissected her laryngeal muscles as fine and accurately as possible and recorded the results in the form of sketches. The cause of her death, as explained shortly, was not a disease of the larynx but was the cancer of an organ in the lower abdominal cavity. Therefore, my dissection was not for pathological anatomy; it was a purely anatomical one.

A chance to make a dissection of the larynx of a world-famous opera-singer is indeed extremely rare as shown by the fact that there have never been reports of this sort as far as I am aware. I believe, therefore, that the results of my dissection should be recorded and left for the future. I am extremely happy that the record of mine is included in this publication which is put out in commemoration of the 70th birthday of Doctor S. Nishi, Emeritus Professor of Tokyo University, who had given me fundamental anatomical trainings to be a laryngologist.

It is my pleasant duty to express my thanks to my teacher, Professor K. Satta, formerly of Tokyo University and now of Tokyo Art University, to Professor I. Kirikae of Tokyo University (Department of Nose-Ear- and Throat) and to Mr. Yutaka Ando, the artist who has prepared the final drawings from my sketches.

\section{The History of Madam Miura as Opera-singer}

She was born in Tokyo in 1884 and graduated from Tokyo Music School in 1904. Her singing career started in 1915 at the London Opera House where she sang for the first time the Madam Butterfly under the air attack of German Zeppelin. Since that time during her twenty years of career as Primadonna in America and Europe, mainly in America, she established a great record of two-thousand 
singing performances of the Madam Butterfly. From 1935 when she returned to Japan till she became a victim of cancer of the lower abdomen and closed her colorful life at Tokyo University Hospital on 26 May, 1946, she had given constant, passionate love to vocal musics as an opera-singer. Her dramatic ability and beautiful voice were widely recognized in Europe and America. Singing of such opera as the Madam Butterfly would, unless a great caution is taken, easily destroy the larynx. She developed, therefore, her own way of singing that fitted her larynx. She says in her autobiography that she is the only singer of the kind whose larynx has not been destroyed from singing operas so many times. The Madam Butterfly which she sang at the age of 63,47 days before her death, while she was suffering from cancer, showed that her. voices were still young and beautiful at that old age.

\section{Method of Dissection}

Accurate results cannot be expected from a simple macroscopic dissection using a magnifier for such complicated muscles as vocal muscle. Gaerttler ${ }^{(2)}$ stated in his paper on the human vocal muscles that studies of these muscles must depend on serial sections. This may be true. However, this method is dangerous to be applied to a specimen such as mine which cannot be replaced by others. A magnifier $(2 \times)$, forceps, knives and elevators made from needles by sharpening the ends to various shapes were used. For the sake of accurasy of observation, methods and techniques were improved whenever possible and a sufficient amount of time was spent for the dissection. What made the muscle preparations difficult were the connective tissues in and around the parts to be dissected and peripheral nerve fibers and minute blood vessels. While these structures were being cut and removed carefully one after another, the muscle fibers and bundles were separated and their directions as well as intertwinements were carefully determined. Microscope was used whenever it was necessary to ascertain the structure such as to find the relation of the muscle fibers to the tendinous fibers of the vocal ligament, or to determine the muscle fibers running within the paraepiglottic and submucous paralaryngeal spaces where vascular, nervous, fatty and connective tissue elements are mixed with the muscle fibers, or when muscle fibers and bundles inserted to connective tissues of the aryepiglottic fold are to be ascertained. 
Although at the beginning of this work which has lasted for five years, it was difficult to differentiate muscle fibers from connective or tendinous fibers, later as I gained experiences through repeated use of microscope, it became easily possible to differentiate them by naked eyes.

\section{Results of the Dissection}

\section{Muscles of the larynx}

1. The crico-thyroid mucles (fig. 1)

The entire muscle is voluminous. It is inserted to even a relatively high portion of the inner surface of lamina of the thyroid cartilage. The length of the insertion area on the thyroid cartilage of the upright and oblique portions is $21 \mathrm{~mm}$ at the lower border of the thyroid cartilage and $11 \mathrm{~mm}$ at the inferior thyroid horn. These are greater than the average figures of the Japanese males which are respectively $20 \mathrm{~mm}$. and $7 \mathrm{~mm}$. according to K. Nihonsugi ${ }^{(3)}$. Slender muscle bundles (the primary or secondary bundles) run in parallel, but those of the oblique portion, chiefly those of the superficial layer, have unipennatus and bipennatus types of fiber arrangement.

2. The posterior crico-arytenoid muscle (fig. 2)

The surface area of this muscle is approximately $207 \mathrm{sq} . \mathrm{mm}$. and it exceeds the average area of the Japanese males which is $154 \mathrm{sq} . \mathrm{mm}$. according to $\mathrm{K}$. Nihonsugi. It is voluminous and the bundle at its lateral part is fused through the connective tissue with the superficial muscle fibers of the transverse arytenoid muscle.

3. The arytenoid muscle (fig. 1,2)

The transverse arytenoid muscle is covered superficially by the extending muscular fibers of the external thyro-arytenoid muscle. The muscle bundle of the surface region of the oblique arytenoid muscle extends to the ary-epiglottic fold and mixed with muscle bundles from the pharyngo-epiglottic muscle or to the epiglotticus. Furthermore, they are mingled with the ary-epiglottic muscle and the thyro-ary-epiglottic muscle.

On the left side there is an upright ary-corniculate muscle (m. ary-corniculatus rectus); and the corniculate cartilage on the left side is bent back more than the right side.

4. The leteral crico-arytenoid muscle (fig. 1, 2)

The lateral crico-arytenoid muscle is larger than the average of 


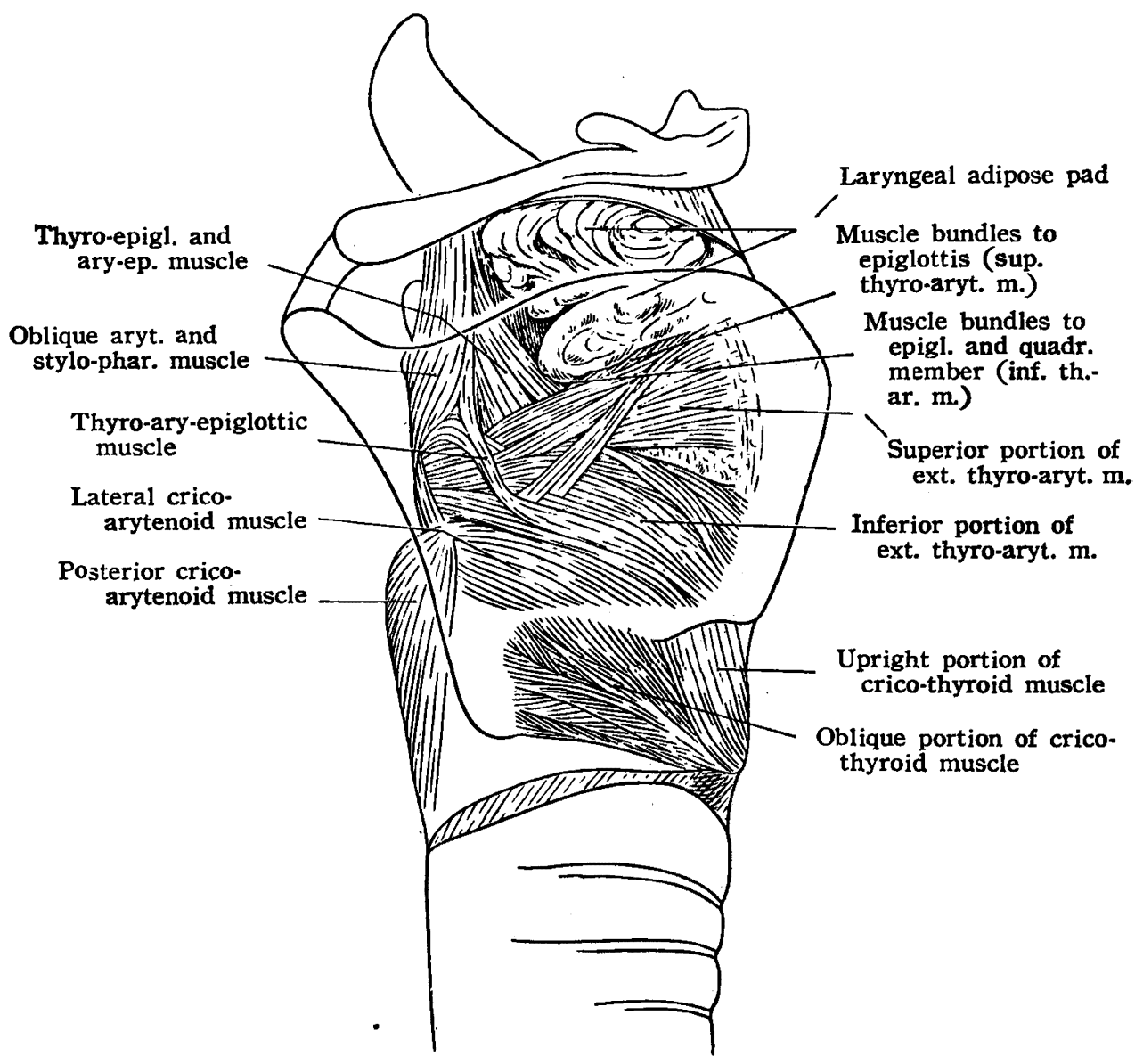

Fig. 1. The right side view of the intrinsic muscles of the larynx of Madam Miura in which the shape and position of the thyroid cartilage are indicated in outline. Note that the adipose pad in the pre- and paraepiglottic space shows an interesting formation. The superior portion of the external thyro-arytenoid muscle sends out from its uppermost part muscle bundles to the side of the epiglottis through the adipose pad, and beneath the superior portion the inferior portion of the external thyro-arytenoid muscle also sends muscle bundles to the epiglottis and divergently to the quadrangular membrane. At the lateral side of the arytenoid cartilage the superficial muscle fibres of the both are intertwined, some of them running to the arytenoid muscle; and between the two portions there is a slit-like fibrous area, the base of which corresponds to the ventricular wall. These fibrous threads crisscross with each other, to which the thyro-vocal muscle is attached by tendinous fibers. The crico-thyroid muscle shows in its oblique portion a fan-like arrangement of the slender muscle bundles with the uni- or bipennatus type. 


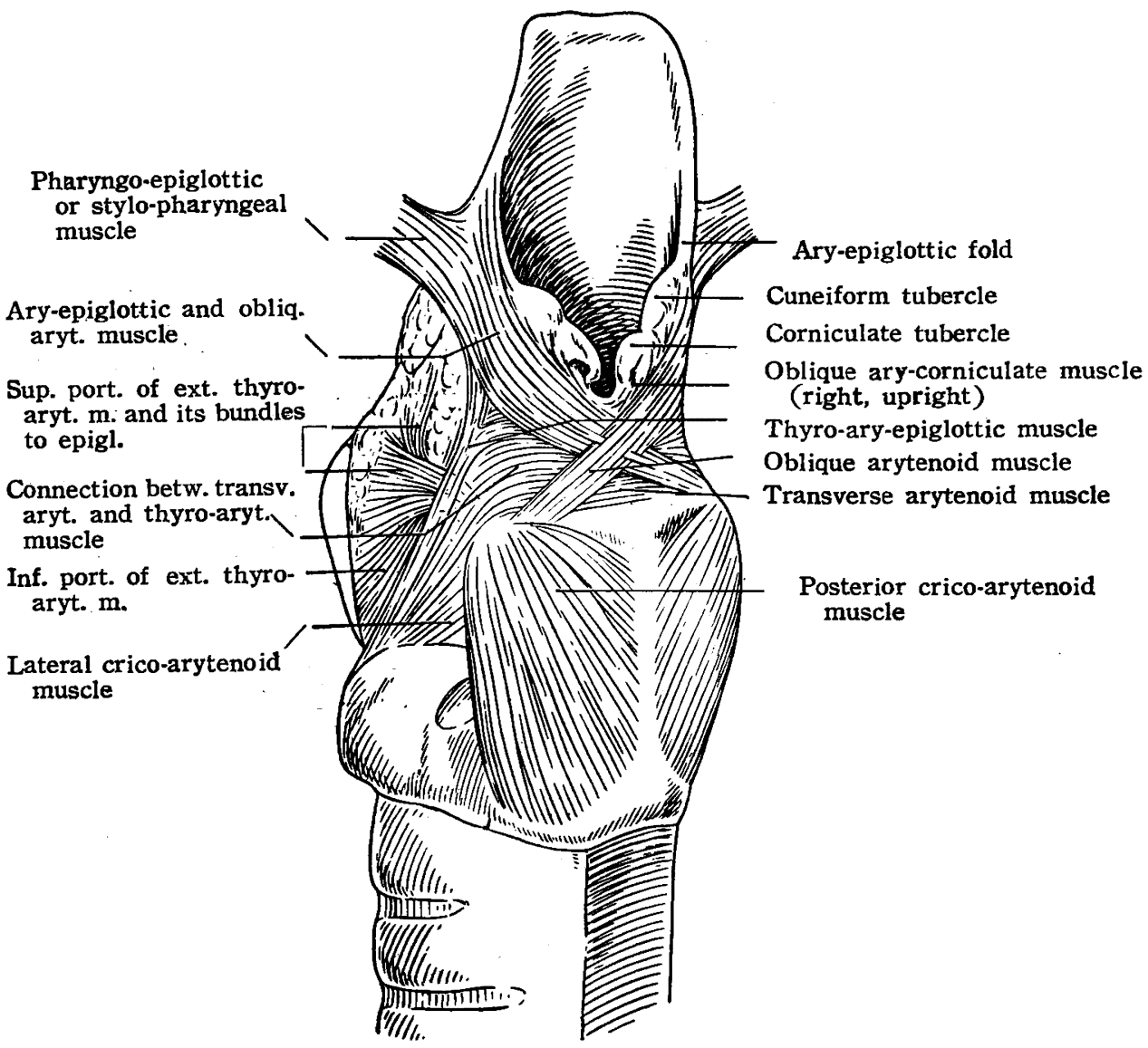

Fig. 2. The intrinsic muscles of the larynx, viewed from left and behind after removal of the left lamina of the thyroid cartilage and the adipose pad. Note that under the thyro-ary-epiglottic muscle and the superficial fibers of the arytenoid muscle, the superior external thyro-arytenoid muscle is shown. The superficial muscular bundles along the aryepiglottic fold consists mainly of the muscle fibers which originate from the pharyngo-epiglottic muscle and the oblique arytenoid muscle and mingle with elastic fibrous threads. Beside these are also bundles below which are of the ary-epiglottic muscle itself.

the Japanese males. The length of the muscle origin is $13 \mathrm{~mm}$. and the total length of the insertion area is $8 \mathrm{~mm}$. The averages of these in the Japanese males are respectively $10.5 \mathrm{~mm}$. and $5.8 \mathrm{~mm}$.

The muscle bundles originating from the elastic cone are large in number on both sides and their surface regions extend into the transverse arytenoid muscle. 


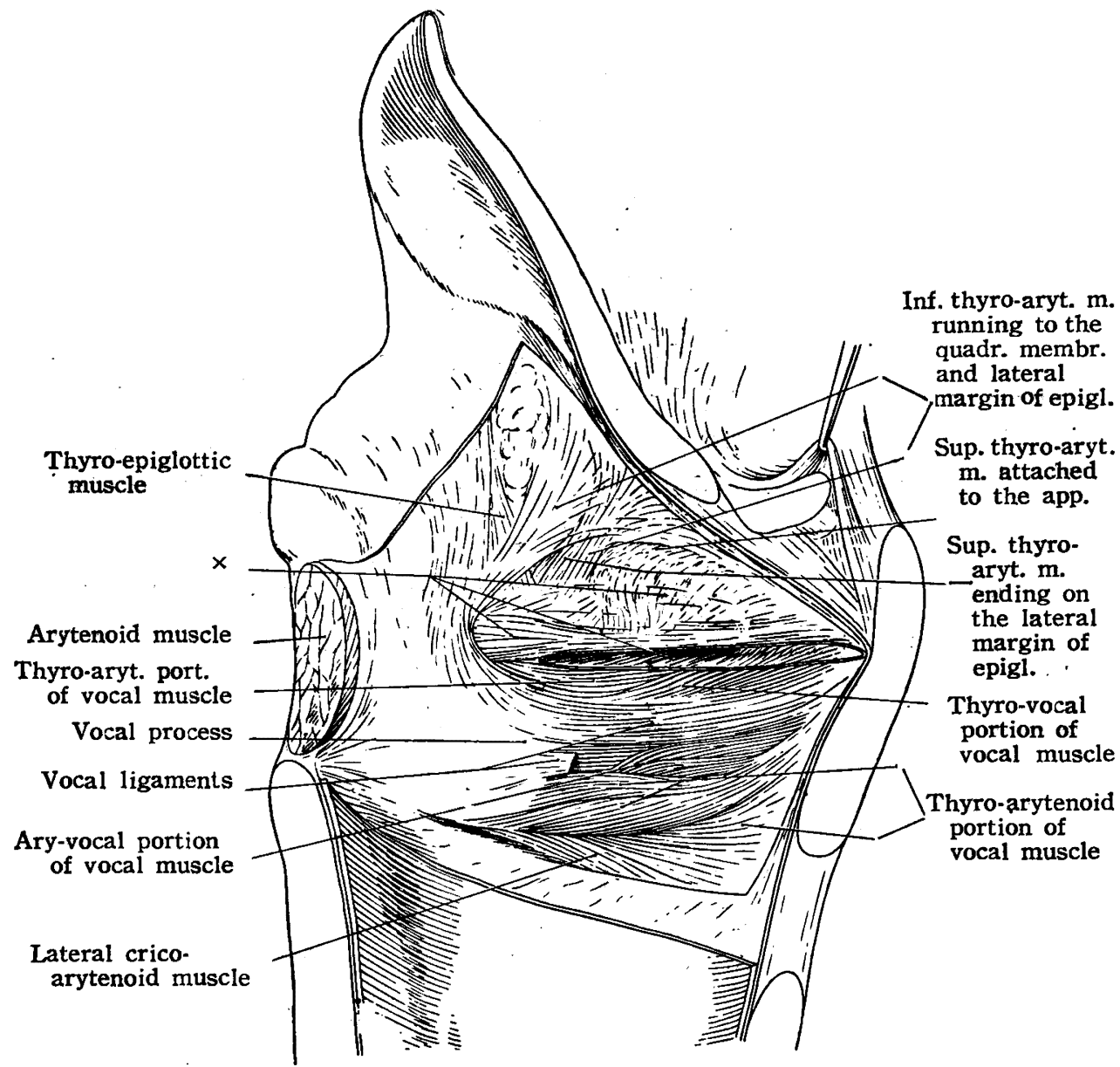

Fig. 3. The inside view of the left midsagittal section of the larynx, showing the vocal and some of the other muscles related to the laryngeal vestibule. Vocal ligaments and elastic cone are removed except its adjoining sheets on the muscle layer to protect it from injuries. Just underneath the vocal ligaments the slanting fibers of the vocal muscle are running inwards beneath the volcal process. When viewed through the covering membrane the following structures are seen: (1) At the upper side of the vestibular ligaments the muscular fibers originating from the arytenoid cartilage and spreading over the quadrangular elastic membrane or ending beneath at the margin of the epiglottis; (2) the fibrous wall of the ventricular appendix.

$\times$ Vestribular ligaments; inlet of ventricular appendix; medial wall of appendix, its fibrous fibers converge downwards upon the middle part of the vestibular fold. 
5. The external thyro-arytenoid muscle (fig. $1,2,3$ )

A distinct feature of this muscle is that its superior or descending portion is very well developed. Muscle bundles with a large number of branches are found to pass through the laryngeal adipose pad and attach to the lateral margin of the epiglottis or they may be attached to the quadrangular membrane. On the right side the bundle at the upper part of the superior portion pinches the upper edge of the appendix of the ventricle, and a part of it sends muscle fibers backward to the vestibular fold. There are plenty of muscle bundles extending from the inferior or ascending portion of this muscle to the quadrangular membrane, the lateral margin of the epiglottis and ary-epiglottic fold. They extend into a part of the transverse arythenoid muscle. They are of extremely complicated types, some being in ary-epiglottic and ary-quadrangular muscle type and some, in ventricular muscle type.

The tendinous fibers run out between the superior and inferior portions of this muscle from the connective tissue of the lateral wall of ventricle and are firmly connected with the muscle bundle. This fiber reaches the vestibular ligament and the ligament of the vocal cords.

6. The internal thyro-arytenoid muscle (vocal muscle) (fig. $3,4,5$ )

The length of the vocal ligament as measured from the vocal process to the thyroid cartilage is $1.5 \mathrm{~cm}$. It is not shorter than those of European and American women. The vocal ligament and the crico-vocal membrane were removed while cautions were taken to avoid injuries on muscles in the layer below and to leave intact the parts adjacent to the muscle layer, and the vocal muscle was observed from inside. Each piece of ligament removed was examined with microscope to see if any muscle elements are left attached to or mixed with it. The muscle fiber in the shallow part transitional to the lateral wall from the base of the ventricle lateral to the free margin of the vocal cord is mixed with the fiber of the ligament or it originates from the thyroid cartilage with the tendinous fiber and runs convergently toward medial and back direction. Its inner part is inserted to the vocal ligament and its outer part is inserted to the posterior portion from the vocal process. And some of these fibers, especially at the middle part, run concavely to the vocal ligament at a comparatively sharp angle, and some slender fibers originating at a somewhat deeper part run between muscle fibers of the shallow layer and they are inserted to the ligament. The most lateral muscle bundle 


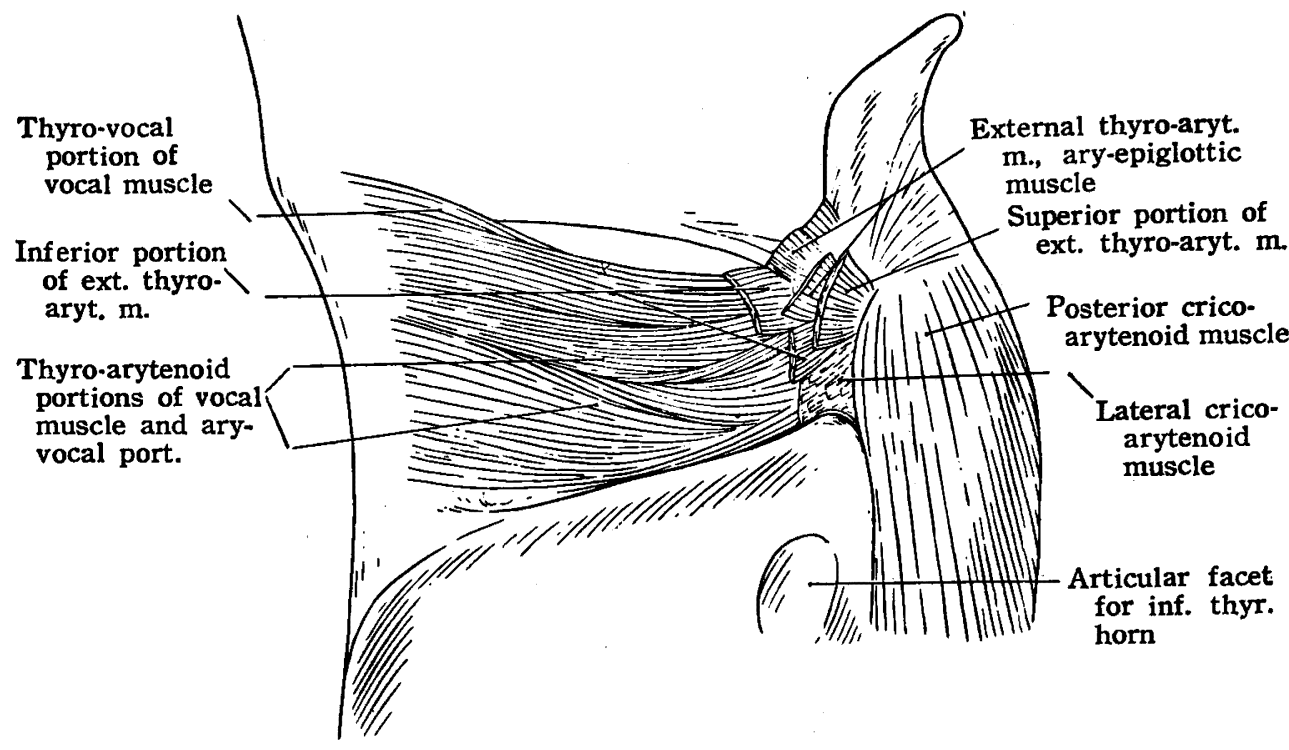

Fig. 4. The part shown in fig. 3 is viewed from outside after the removal of the external thyro-arytenoid muscle. The part indicated by $x$ corresponds to the part shown by the same mark in fig. 3 .

of this part are inserted to the arytenoid cartilage at the medial side of the region where the vestibular ligament is attached to the arytenoid. This arises from the muscle fiber at the upper portion of the inferior part of the external thyro-arytenoid muscle and the lateral fibrous wall of the ventricle.

At the portion caudal to the free edge of the vocal ligament, the shallow layer of the vocal muscle arises from the lower border of the vocal process and running somewhat convergently it is inserted to the front end of the thyroid cartilage. The bundle at its lowest part is firmly attached to the elastic cone. At the upper part, are fibers which arise or terminate, being mixed with ligaments. In the inner layer is the fiber which arises from the thyroid cartilage and ligament, runs backward, changes its direction caudo-dorsally at a comparatively sharp angle without being inserted to the tip of the vocal process and enters into the muscle entanglement at the front lower part of the vocal process (fig. 3). In the muscle bundle extending to the shallow layer, the fiber arising from the thyroid cartilage reaching mainly to the arytenoid and the fiber arising from the vocal process at the anterior border of the fovea oblongata and reaching the vocal ligament intertwine at the front lower part of the vocal process (fig. 5). 


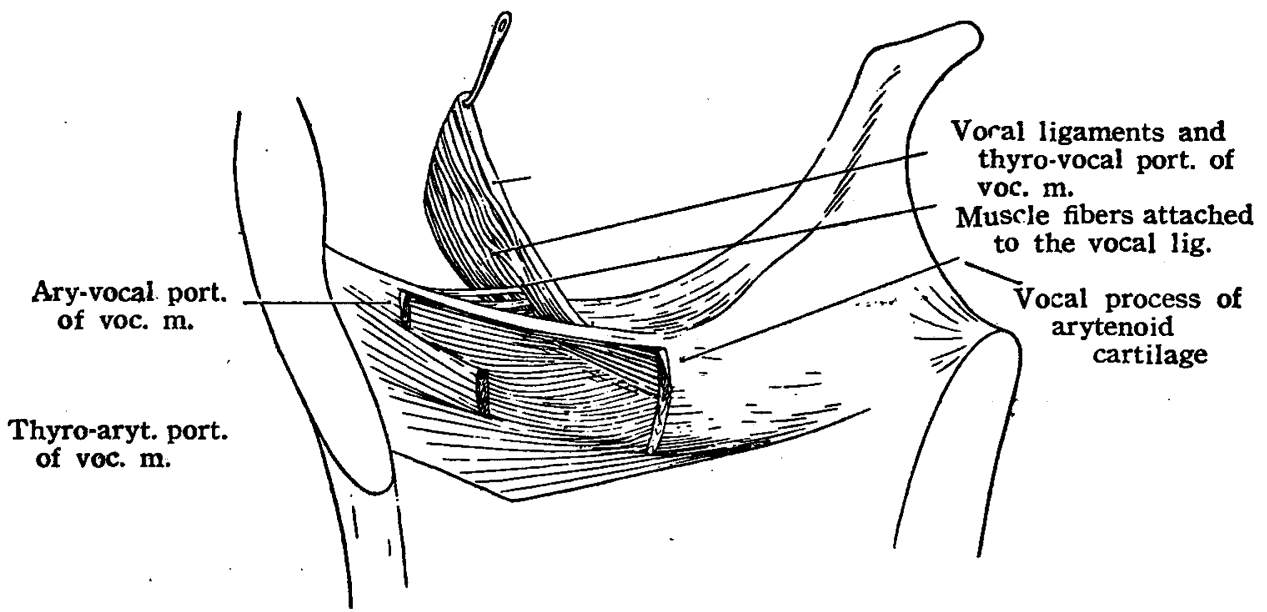

Fig. 5. A detailed view of the right vocal muscle as seen from inside (semischematic drawing). Note that the superficial muscle bundles which can be separated from the under layer are partly cut off and vocal ligaments with their muscle fibers are turned upwards in order to demonstrate the ending and the course of the muscle fibers.

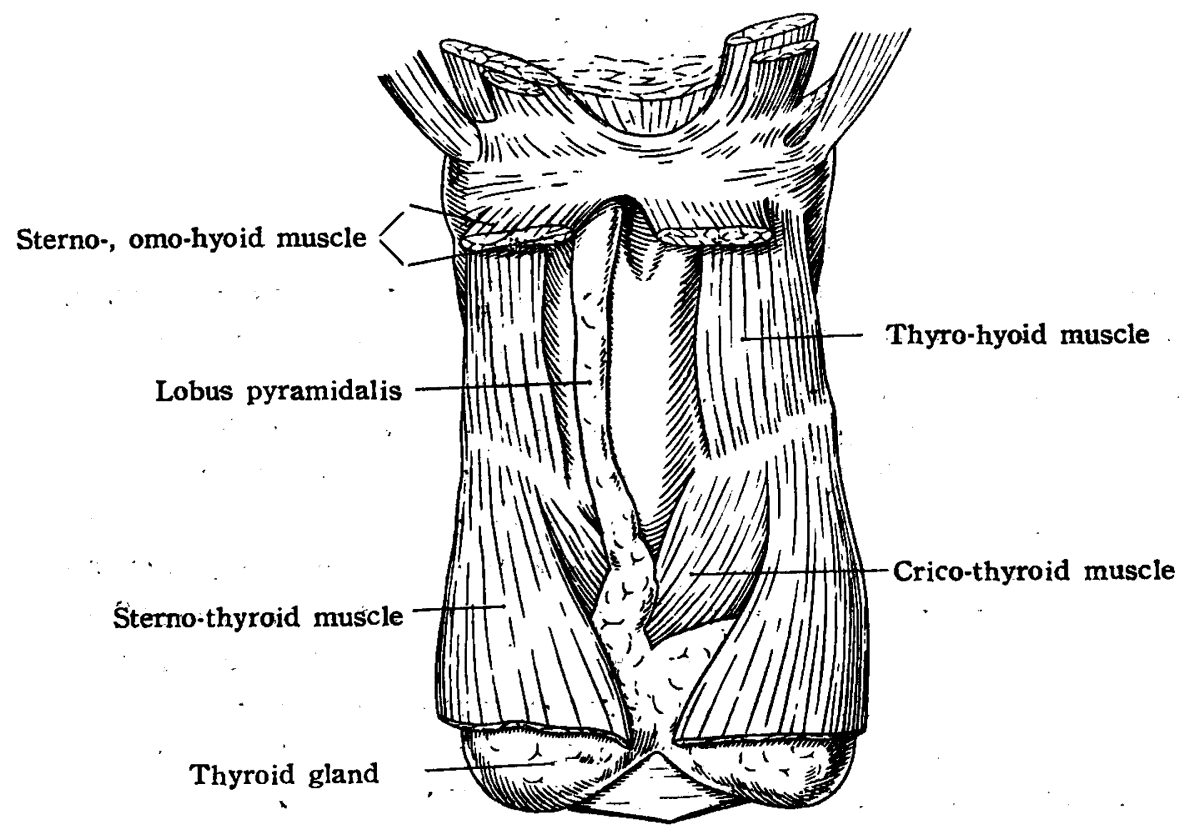

Fig. 6. Front view of the larynx, showing the subhyoid muscles and the thyroid gland. 


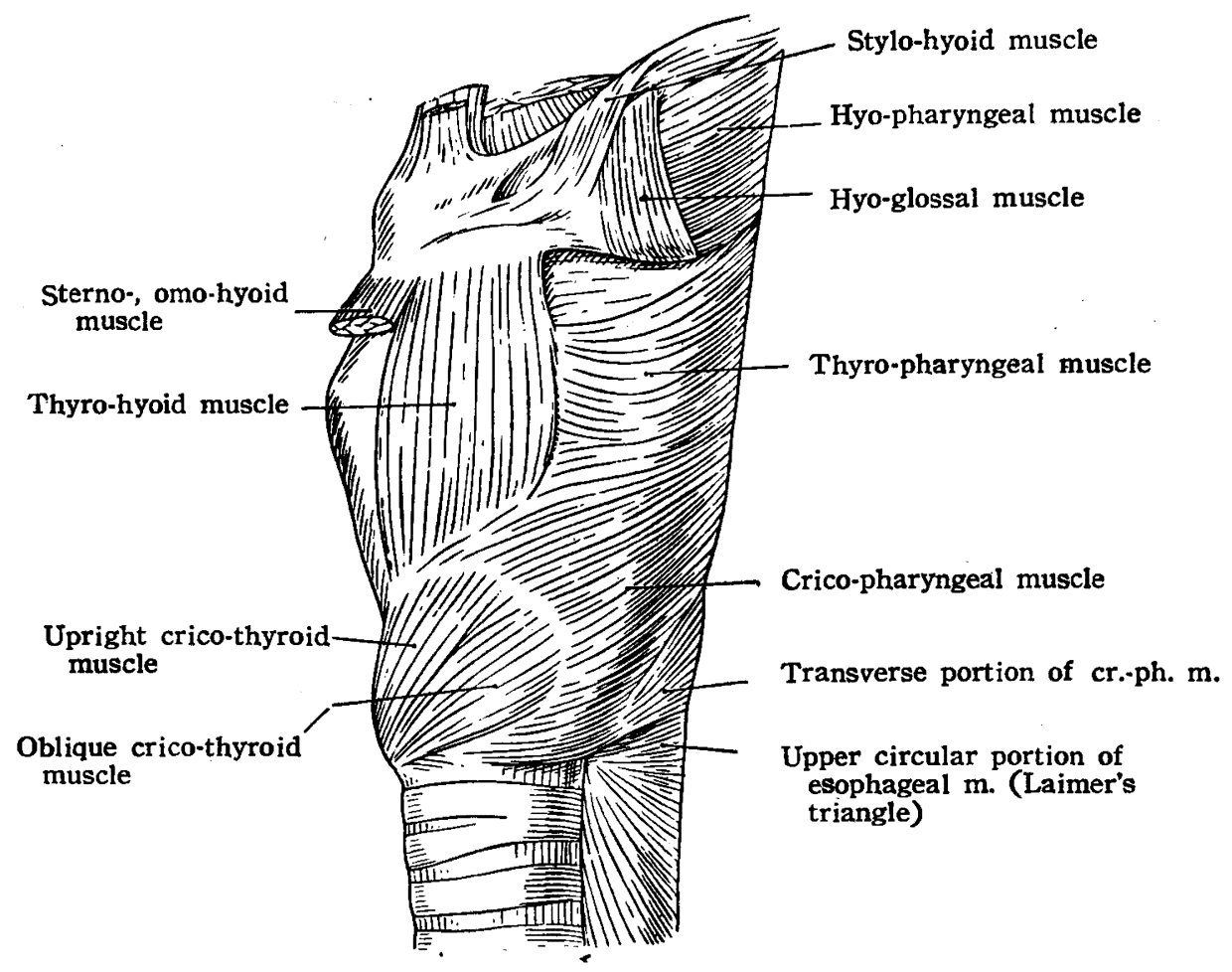

Fig. 7. Lateral view of the part shown in fig. 6. after the removal of the sterno-hyoid muscle and the thyroid gland. The crico-thyroid and laryngo-pharyngeal muscle are shown.

Further, here is a nerve plexus surrounded by connective tissue. These nerve fibers run to the mucous membrane from not only the muscle fibers but the elastic cone also.

The vocal muscle as seen from outside is shown in fig. 4. The middle part of the figure where muscles shown to be intertwined is the part near the vocal cord. The fibers of the vocal muscle are more closely interwoven as they approach closer to the vocal cord and to the center of the vocal lip and the bundle structure becomes more slender. And near the vocal ligament, its tendinous fiber and the internal perimysium of the muscle bundle seem to be connected. Also at the central part, there are a number of muscle fibers ending at the connective tissue there (internal perimysium).

What have been described above are the essential features of the vocal muscle of Madam Miura's larynx. Fundamentally these seem 


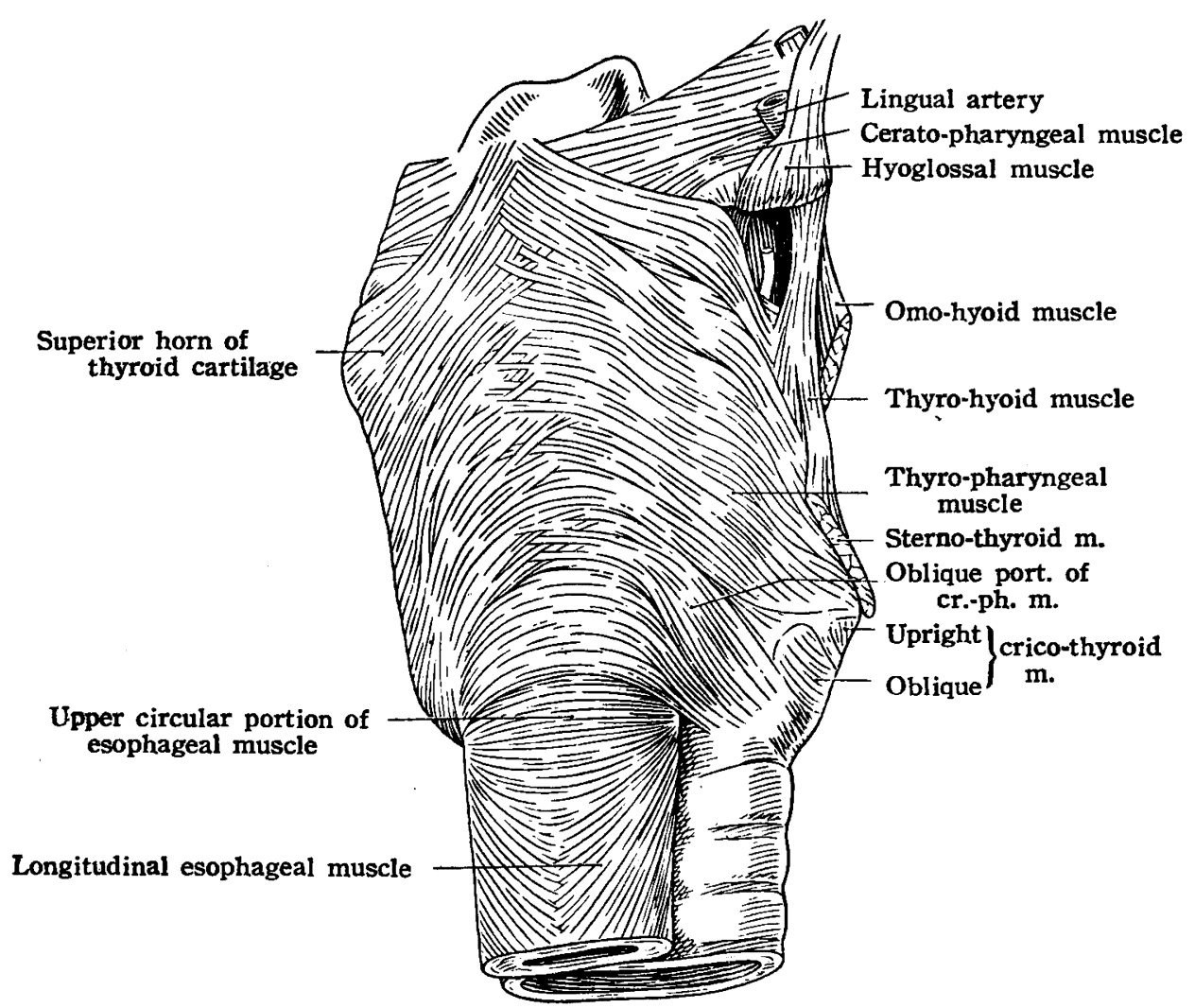

Fig. 8. Muscles of the hypopharynx and the cervical esophagus viewed from behind and slightly to the right.

to coinside well with the structure of the vocal muscle drawn schematically by Gaerttler. I was unable to show in a clear, stratigraphic manner like his schematic figures the ary-vocal muscle, the thyrovocal muscle and the thyro-arytenoid muscle. However, I believe that what have been presented above indicate well the structure of the muscles which may be considered in relation to the phonetical activities or abilities of her vocal cord.

Some of the further details found from my observations may be added here.

1. The subhyoid muscle (fig. 6,7 )

Only the parts attached to the larynx and the hyoid bone were observed. They were well developed. No variations or aberrations were found.

2. The thyroid gland (fig. 6) 


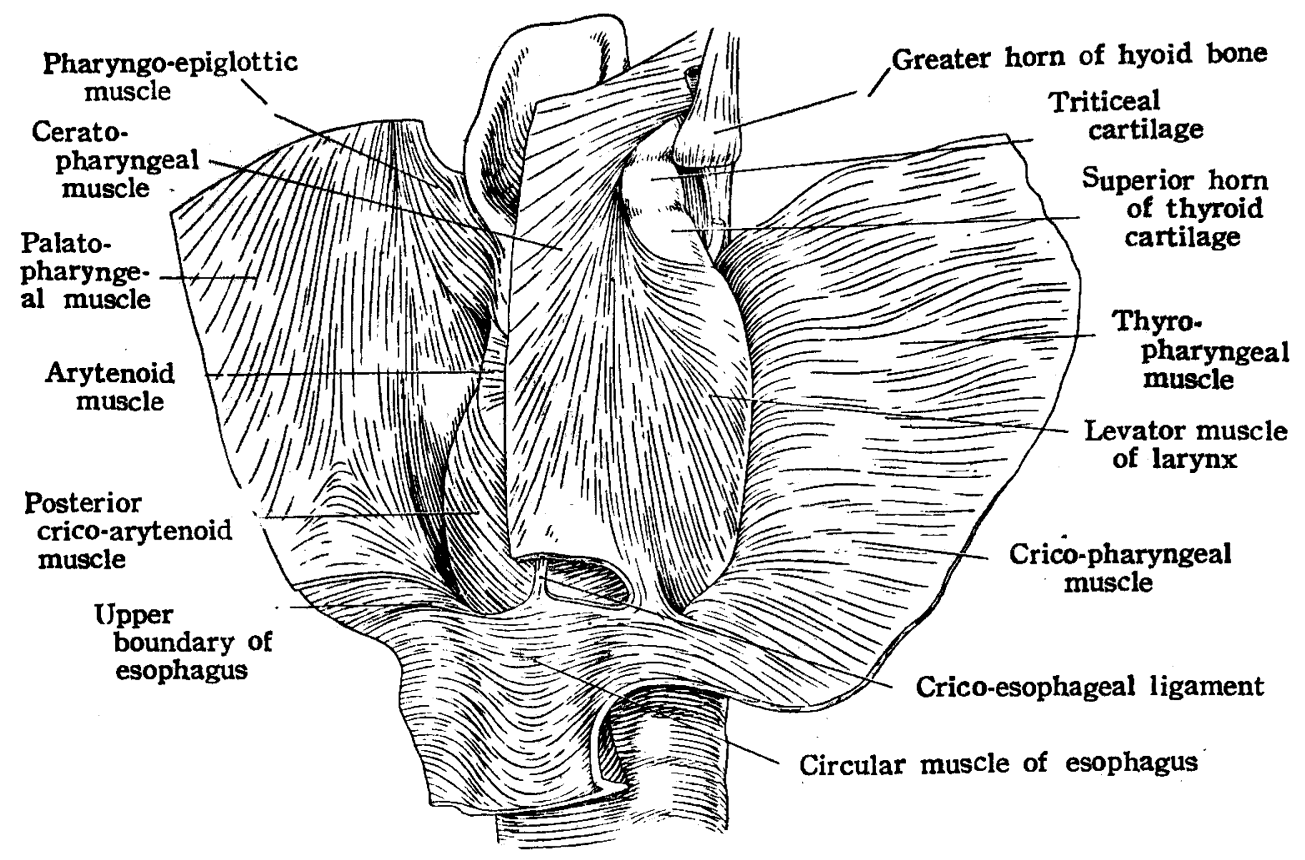

Fig. 9. Inside view of the part shown in fig. 8 from the same direction. In the preparation drawn in this figure the muscle is cut open along the midline and then the muscle on the right side is split into two layers.

This organ was shriveled due to a long storage in formaldehyde solution. The lobus pyramidalis was found on the right side, but no variant muscle was observed.

3. Pharyngeal muscle and the upper part of the oesophagus (fig. 8, 9).

I was able to make observations of the part shown in the figures. Although no particular differences from ordinary cases were found, I paid attention to the relation between the hypopharyngeal muscle and the upper marginal muscle of the oesophagus. The closest connection of the two in the Laimer's triangle is seen at the most dorsal part. The two-layer muscles at the upper part of the oesophagus converge toward the lateral wall and form a voluminous muscle bundle.

\section{Summary}

The laryngeal muscles of Madam Tamaki Miura, primadonna of the Madam Butterfly, were dissected and anatomical observations were made with the following results: 
1. Every muscle is of large scale and exceeds the average size of the Japanese males. The lengths of the vocal cords are no less than those of European and American women.

2. The uni- or bipennatus type of muscle bundle is arranged in the oblique crico-thyoid muscle. This seems to have a dynamic meaning.

3. There is a distinct intermingling between the arytenoid muscle and the lateral crico-arytenoid muscle or external thyro-arytenoid muscle. In the aryepiglottic fold, the muscle bundles of the oblique arytenoid, pharyngo-epiglottic, ary-epiglottic and thyro-epiglottic muscle join and blend with each other, forming the sphincter at the entrance to the larynx. Some of these muscle fibers are inserted to the fibrous tissue of the ary-epiglottic fold and. give partial changes to the fold.

4. The superior thyro-arytenoid muscle expands widely above the level of the vocal cords and sends out a number of muscle bundles to the elastic membrane of the suprarimal as well as to the epiglottis. Such a muscular development seems to be advantageous for the coordination with a better tone production.

5. The vocal muscle consists of the ary-vocal, thyro-vocal and thyro-arytenoid muscles. In the vocal ligament, it is connected with its tendinous fibers and the perimysium of the slender muscle bundle from the surface or somewhat deeper layer at various angles. At the central part in front and below the vocal process, the muscle bundles are arranged densely and somewhat irregularly and there a nerve fiber in the form of plexus is observed. These are considered to be useful for partially controlling the vocal cords.

6. From the quantitative and qualitative features of the muscles described above, Madam Miura's larynx is judged to be anatomically very well developed. However, it should be pointed out that her larynx was developed well as an instrument and that she developed herself to a great opera-singer by her own long endeavor to improve her technique and musicianship.

\section{Literature}

1. Oishi, K. Systematic observations on the hyoid, pharyngeal and laryngeal muscles in primates. Tokyo Igakkwai Zassi, v. 55, 1941. (In Japanese)

2. Goerttler, K. Die Anordnung, Histologie und Histogenese der quergestreiften Muskulatur' im menschlichen Stimmband. Z. Anat. u. Entw.-gesch., v. 115, 1950.

3. Nihonsugi, K. On the laryngeal musculature of the Japanese. Acta Scholae Med. Univ. Imp. Kioto, v. 5, 1922. 